\title{
Ensuring Healthy Teacher-Student Relationship in Mathematics and Science Classes through Strategic Classroom Management
}

\author{
Mimi Martha CHIANSON PhD \\ Benue State University, Makurdi \\ Benue State, Nigeria \\ E-mail: searchhbk@yahoo.com \\ Eriba Emmanuel OTOR PhD (Corresponding author) \\ Benue State University, Makurdi \\ Benue State, Nigeria \\ E-mail: otoreribaemmanuel@gmail.com Tel: 80-678-90-766
}

Received: December 1, 2014 Accepted: January20, 2015 Published: January 23, 2015

doi:10.5296/ire.v3i1.7000ＵRL: http://dx.doi.org/10.5296/ire.v3i1.7000

\begin{abstract}
In our efforts to build a veritable educational system and develop genuine intellectual skills, the challenges of our classroom management must not be undermined. The classroom management of mathematics and science which are one coil with different faces is the thrust of this article. It is believed that effective classroom management among mathematics and science teachers would enhance class control, discipline, good conduct and improve instructional attainment. This paper identifies a strategic classroom management as a process by which teachers analyze the internal and external environment for the purpose of formulating strategic and allocating relevant resources to develop students' intellectual abilities. The paper highlights three main components of classroom management to include content management, conduct management and covenant management. Principles of strategic classroom management were also discussed. It recommended that mathematics and science teachers should choose strategic classroom management procedures that can help sustain and maintain a health classroom interaction for free flow of learning.
\end{abstract}


Keywords: strategic management, content management, conduct management, covenant management, effective teaching, teaching environment.

\section{Introduction}

A few cases exist in the contemporary classroom situation where one can find the teacher and students having good rapport. Some teachers tend to be too harsh and undiplomatic dealing with various students' behavior on the other hand; students are disorderly and uncoordinated during class activities as noticed and observed from our few years experience in teaching at the post- primary level. These issues may prevail and be in existence in a good number of class situations for which mathematics and science classes can definitely not be exempted.

Teachers of mathematics and science deal with and find difficult situations of poor instructional procedure, poor classroom control, discipline and classroom management and management of students conduct are skills that science and mathematics teachers acquire and hone over time. It is pertinent that, for teachers to manage the classroom with little hitches, such a teacher is surely an effective teacher. To affirm this, effective teaching by teachers requires considerable skills in managing the myriad of tasks and situations that occur in the classroom each day (Kizlik, 2014). Science and mathematics teachers play various roles in a typical classroom, but surely of the most important and difficult is that of classroom manager. Everton and Weinstein (2006) look at classroom management as having two distinct purpose "it not only seeks to establish and sustain an orderly environment so students can engage in meaningful academic learning, it also aims to enhance students social and moral growth” (p. 4)

Atanda and Lameed (2000) simply describe classroom management as involving the utilization of material resources and securing the cooperation of students for performing the functions of planning, organizing, directing and coordinating at classroom level by teachers so as to achieve maximum results. For mathematics and science teachers to be able to maintain and attain orderly and organized class situations, they must initiate some strategic management procedure to accomplish this purpose.

Krause, Bochner and Duchesne (2003) define classroom management as being concerned with behaivour and can also be seen as planning, organizing and controlling the learners, learning process and classroom environment to create and maintain an effective learning experience. Tan, Parsons Hunsons and Sardo-Brown (2003) see classroom management as a term used to highlight all of the positive behaviour and decisions teachers make to facilitate the learning process of their students. It refers to all those activities necessary to create and maintain an orderly learning environment such as planning and preparation of material, organization, decorative of the classroom and certainly establishing an enforcement of routines and rules. In a nutshell, classroom management is teacher's strategies that create and maintain an orderly learning environment and discipline and teachers resiponses to students' misbehaviour.

Some researchers define classroom management as the range of teacher's effort to oversee classroom activities, including learning, social interaction and student behaivour (Burden, 
2005; Good \&Brophy, 2006). Mathematics and science teachers are saddled with the responsibility of making sure students conduct themselves appropriately in a group, during learning and classroom activities. Teachers should be vigilante to see that as classroom activity progresses; students should flow with and be at ease with the goings- on in class.

Another researcher sees classroom management as a teacher's efforts to establish and maintain the classroom as an effective environment for teaching and learming (Brophy, 1986 in Unal\&Unal, 2012). Shakir (2014) views classroom management as a means for teachers to arrive at answers to student's misbehaivour which is often connected to motivation, discipline and respect in the classroom.

McCreary (2014) defines classroom management as the methods and strategies an educator uses to maintain a classroom environment that is conducive to students' success and learning. Teachers like to define classroom management as the process of ensuring that classroom lessons run smoothly despite disruptive behaviour by students. The term can also go for prevention of disruptive behaviour. Many science and mathematics teachers establish rules and procedures at the beginning of a classroom session to help monitor and maintain orderliness in class. It is however obvious that managing students' behaviour is clearly a complex process. Teachers need to be multi-skilled, talented and able to deal with a range of different behaviour coming from their students.

A lot of theories postulated have educational implications on classroom management; one of such theory is that of Kounin (1977). The authors' first observation of an intriguing pattern in students' behaviour took place in his classroom. When he asked a student to put a distractful object away, he noticed that the students around him were forced to maintain focus and pay attention. He discovered that correction in one student behaviour actually affects others hence, making them disengage from inappropriate behaviour. This phenomenon was described as "Ripple effect". He concluded that in order for a teacher to have effective connection between management and teaching, they needed to be good lesson movement. This movement is adhered through with-it-ness, overlapping, momentum, smoothness and group focus.

To maintain with-it-ness, the teacher strives to maintain eye contact to all students at all times. The use of non-verbal techniques is to show students that he is alert and cares about the well-being of all students. The teacher should know each student on a personal basis and make respectable suggestions to inform the students that their behaviour is unacceptable.

In overlapping, a teacher should be multitasking that is being able to present topics in class and as well prevent misbehaviour. In momentum, the teacher ensure that he makes lectures short to allow students to group together and move around groups to gain more knowledge of the content. For smoothness, the teacher establishes rules that, students need to make hand gestures when trying to make comments or ask questions in class. This helps to know students who may cause an unwanted tangent and those who may have good questions to ask.

For group focus, the teacher engages the whole class using techniques such as building suspense or asking community questions. This can also be in form of random questions. The teacher uses this aspect to hold students accountable and responsible for their actions and 
make them realize that grades are awarded based on participation and contributions to group task. This makes students more focused and motivated to commit to classroom activity and get less involved in class disturbance.

Strategic management as defined by Ovidijus (2013) is a process by which teachers analyze the internal and external environment for the purpose of formulating strategies and allocating relevant resources to develop students' abilities and allow for successful achievement of school objectives and goals. Literally strategic management can be perceived as the process of working out what should be done and how it could be done to achieve a particular organizational set goal. Udeozor (2012) defined strategic classroom management as the process of deliberately concentrating the resources of a classroom towards the achievement of certain desired and designed instructional goals.

It is a well known fact that all activities in the classroom is geared towards goals achievement. According to Froyen and Iverson (1999) school and classroom management aims at encouraging and establishing student self-control through the process of promoting positive students achievement, and behaviour. Thus academic achievement, teacher efficacy and teacher/student relationship are directly linked with the concept of school and classroom management.

Mathematics and science teachers can achieve proper classroom management by being proactive. The teacher needs to know what to do and how best to do it. He needs patience, needs to be vigilant when addressing issues in the classroom. The teacher needs to be aware that students come from diverse culture and have different orientation and background. What may appeal to one, may not appeal to the other, hence his strategic classroom management practice must be multifaceted and not a one size fit all approach. The teachers' ability to be aware of these issues may promote a healthy relationship between him and his students. Mathematics and science teachers need to consider also that the level of success of his class will be attributed to the strategic classroom management approach being utilized.

\section{Components of Classroom Management}

Classroom management focuses on three main components namely; content management, conduct management and covenant management (Froyen\& Iverson, 1999).

\subsection{Content Management}

This occurs when teachers manage space, materials, equipment, movement of people and lessons that are part of a curriculum or program of studies (Monjardin-Esdicul, 2009). In respect to this, mathematics and science teachers who find it difficult to manage such resources at their disposal, fail to plan and design appropriate instructional tasks. They seem to neglect variety in lesson plans and rarely prompt students to discuss or evaluate the materials that they are learning. Content management may not necessiarily refer to skill peculiar to teaching a particular subject but rather to those skills that cut across certain classroom subjects and activities. With respect to content management, special emphasis should be placed on instructional management skills, sequencing and integrating additional activities and dealing with instruction related discipline problems. This can help to curb 
classroom management situations.

\subsection{Conduct Management}

This is centred on one's belief about the nature of people and discipline (Doyle, 2011). By integrating knowledge about human diversity and individuality into a particular instructional philosophy, teachers could manage their classroom in a better or more effective way. In planning classroom management, teachers should consider using an assertive communication style and behaviour. They should enlighten the students on what students need to be doing and what respective learning activities they need to get involved under clearly stated classroom rules. An effective conduct management plan refers to teacher control and administration of consequences. These include correcting irresponsible and inappropriate behaviour, gentle verbal reprimands, setting limits outside the classroom and reinforcement systems.

\subsection{Covenant Management}

This stresses classroom group as a social system. Mathematics and science teachers with their students have roles to play. This expectations helps in shaping the classroom into an environment and conducive to learn. In other words, the culture of any given school is unique to such a school; however, it is directly influenced by the culture of the larger community whose educational goals are to be met. This approach believes that every student seeks to have a relationship with their teacher that fosters learning (Lafortune, 2014)

\section{Principles of Strategic Classroom Management}

\subsection{Reflecting Students’ Development Needs Students’ Characters}

For a science and mathematics teacher to achieve classroom management needs, student developmental level should be of valued importance. The goals of classroom management should reflect the ever changing needs of students of different learning level. Students who are slow and fast learners should be considered and their development and cognitive needs be met. Marzano, Marzano, and Pickering (2003) assert that 18 percent of studentsi have special needs and require beyond the typical resources available to the classroom. Although, the classroom teacher is certainly not in a position to directly address such severe probllems, teachers with effective classroom management skills have a repertoire of specific techniques for meeting of students needs.

The development processes and general characteristics vary for each individual student. That is as they progress from primary through secondary to post secondary, their affection for teachers is likely to decrease and they are more likely to question teachers' authority. This trend peaks in early adolescence making classroom management at this age challenging. As such, students of all levels of development need the emotional security of knowing that their teachers are genuinely have their interest at heart and sincerely care about their learning. If this attitude is projected by mathematics and science teachers, this will help curb some classroom management situations. 


\subsection{Creating a Favourable Learning Environment}

creating and implementing an appraised learning environment for the science and mathematics students, means planning for both the physical space and cognitive space. It is rather very motivating for mathematics and science teachers to create an environment conducive to concentrate, study and learn more than having attractive, stimulating sights and relating sounds which will take students interest from the teaching or even make them to sleep off. The learning environment should be a place where all feel comfortable, are at rease, a place where the surroundings are neat and orderly to prevent unnecessary conflict and reduce physical emotions violence (Basic principles of classroom management, 2010). It should be a place where there is mutual respect in a friendly, non- threatening atmosphere, a place where everyone can bloom and do their best. The cognitive space necessary for learning should as well be considered. Mathematics and science teachers should create and implement classroom management practices that cultivate an engaging classroom environment for their students.

\subsection{Creating a Physical Environment}

Classroom management focuses on the physical environment. The physical structure of a classroom is a critical variable in effecting student morale and learning (Phillips, 2004). It is pertinent and very necessary that desk and furnishing arrangements in the classroom should be taken seriously. Arranging desks and furnishing is often a compromise between what the teacher would like and what is possible. The physical space of a classroom is managed as the teacher prepares the classroom for the students. Questions a mathematics and science teacher should ask to help ensure a conducive physical learning space are: Is the physical learning space warm and inviting? Does the room arrangement match the teacher's philosophy of learning? Do students have access to necessary materials? Are all distracting features of the classroom eliminated? Attending to these and similar questions, aids a teacher in managing the physical space with ease. Therefore mathematics and science teachers should think about their classroom arrangement when the plan, change according to their goals and experiment to see what works best for them.

\subsection{Creating, Teaching and Maintaining Rules and Procedures}

Every mathematics and science teacher is bound to experience numerous disciplinary problems in the classroom. Therefore, it is important that your student know from the beginning what your rules and expectations are and who is in charge (Meador, 2014). One strategic way to effectively manage class situations is by establishing classroom rules on the teachers first day in class and subsequently during teaching. In initiating of procedures and rules for the classroom, it is imperative to consider students characteristics and the physical environment. Teachers are to employ procedures which when practiced on regular basis become a routine for students. These routines provide a sense of regularity and equilibrium for both students and teachers. For example students must be made to understand that completing and submitting of given assignments in due time is very important and late incoming or missing homework will be handled strictly. These procedures gradually help in curbing classroom situations of this sort. Rules should be descriptions of standards for acceptable classroom behaviour, such as, "listening when someone else is talking". "Taking corrections peacefully and in good 
faith”.Mathematics and science teachers should also limit the number of rulles to be established in class, but rather fix their minds on the most essential and needed rules for the class.

\subsection{Effectively Managing Classroom Activities}

To effectively manage classroom situations a mathematics and science teacher must possess qualities of an effective teacher. According to Kounin (1977), effective teachers differ from ineffective teachers not in the way they respond to students' misbehavior but instead in how competently they manage the group activities. In essence, one can say an effective mathematics and science teacher intending to strategically manage the class can do so using four methods of teaching.

\subsubsection{Show How They Are "With It"}

This implies teachers closely monitoring students on a regular basis and being aware of what is happening. This enables them detect inappropriate behaviour early before it gets out of hand.

\subsubsection{Cope Effectively with Overlapping Situation}

Some teachers seem to have a one-track mind; tending to deal with only one thing at a time. This is an ineffective strategy that leads to frequent interruptions in the flow of the class.

\subsubsection{Maintain Smoothness and Continuity in Lessons}

To maintain effectiveness in teaching, mathematics and science teachers will need to keep the flow of lesson moving smoothly, maintaining students' interest and not giving room or openness to easy distractions.

\subsubsection{Engage Students in Variety of Challenging Activities}

Effective teachers thoughtfully engage students in a variety of challenging but not overly hard activities. Students should be left to work independently rather than being directly supervised by a teacher who hovers over them.

\subsection{Getting Students to Cooperate}

There are three main strategies to get students to cooperate (Cangelosi, 2014). These strategies are as follows:

\subsubsection{Develop a Positive Relationship with Students}

If teachers genuinely show students they care about them aside the regular academic work, it will help them to earn their cooperation. This attention would create a classroom environment in which students feel safe and secure and feel they are being treated fairly. Students will get closer and feel free with teachers, in this way teachers will get sensitive to the needs and anxiety of students. With this, good communication skills will be developed thereby making classroom atmosphere feel more relaxed and pleasant.

\subsubsection{Get Students to Share and Assume Responsibility}

Teachers should afford to share responsibility with students in classroom decision making, 
this increases students' commitment to these decisions. Mathematics and science teachers should endeavour to involve students in the planning and implementation of school and classroom initiatives. Encourage students to judge their own classroom behaviour. Restrain from accepting trivial excuses from students who possibly just want to avoid responsibilities. Allow students participate in decision making by holding classroom meetings.

\subsubsection{Reward Appropriate Behaviour}

In the course of teaching, when a mathematics and science teacher find out that some particular students are not paying attention, he/she can decide to praise other students in the same class for appropriate behaviour. The teacher can make a big deal out of the accepted behaviour to make sure the target student(s) hear the praises. As soon as the target student(s) hear the praise and amend his ways, the teacher should quickly praise the student too. What simply would take place is that, the teacher has given the target student(s) the attention when appropriate and not when the behaviour is inappropriate. If the student(s) appreciates and likes the attention, they will then increase appropriate behaviour to gain more attention.

\section{Conclusion/Recommendations}

This work focuses mainly on some basic strategic classroom management approaches mathematics and science teachers can utilize to keep a healthy teacher-student relationship. Classroom management is certainly not an easy task for both old time teachers and freshers. It requires competence and effectiveness on the part of the teacher. A teacher can fulfill his responsibility of classroom management if he understands the psychology of the students, their background, academic difficulties, cognitive disabilities, coupled with the physical environment. This will help him trace the root cause of the situation and forge ahead to address the situation. The teacher is free to provide rules and procedures and make sure they are maintained and accepted by students. The psychology of students is such that once they realize that a teacher gives attention to another student, they crave to get such attention, this can make them amend their ways; desist from inappropriate behaviour just to get the teachers attention. Classroom management should aim at encouraging and establishing student self-control through a process of promoting positive student achievement and behaviour.

In the light of this, it is recommended that mathematics and science teachers should choose strategic classroom management procedures that can help sustain and maintain a good relationship, provide an orderly learning environment for free flow of learning activities and students ardent cooperation.

\section{Acknowledgements}

We want to at this point thank all authors and authorities whose work we made reference to and cited which boosted the authenticity of this work. Their vast and numerous ideas helped to move this work to a greater level.

\section{References}

Atanda, I., \& Lameed, W. (2006). Fundamentals of school organization and classroom management. Ibadan: Awemark Industrial Printers. 


\section{Macrothink}

International Research in Education

ISSN 2327-5499

2015, Vol. 3, No. 1

Basic principles of classroom management. (2008). Retrieved from www.wikieducator.org/...management.../Basic_...

Burden, P. R. (2005). Powerful classroom management strategies: Motivation students to learn. Thousand Oaks, CA: Corwin Press.

Cangelosi, J. S. (2014). Classroom management strategies: Gaining and maintaining students' cooperation. Retrieved from www.amazon.com/classroom...strategies...

Doyle, W. (2011). Classroom organization and management. In C. M. Wittrock (Ed.) Handbook of research on teaching (4th ed.). New York: Macmillan Publishing. Retrieved from www.intime.uniedu/model/teacher/tec.3summaryhtml.

Everston, C. M., \& Weinstein, C. S. (2006). Classroom management as a field of inquiry. In C. M. Everston \& C. S. Weinstein (Eds), Handbook of classroom: research, practice and contemporary issues (pp. 3-16). Mahway, NJ: Lawrence Erlbaum Associates.

Froyen, L. A., \& Iverson, A. M. (1999). The reflective educator - leader (3rd ed.). Upper Saddle River, NJ: Prentice-Hall.

Good, T. L., \& Brophy, J. E. (2006). Looking in classroom (8th ed.). New York: Longman.

Kizlik, B. (2014). Effective classroom management and managing student. Retrieved from www.adprime.com/managing.htm

Kounin, J. S. (1977). Discipline and group management in classrooms. Huntington, NY: R.E. Krieger.

Krause, K. L., Bochner, S., \& Duchesne, S. (2003). Educational psychology for learning and teaching. Australia: Thomson.

Lafortune, A. (2014). Classroom management trends. Retrieved from www.termpaperwarehouse.com/

Marzono, R. J., Marzono, J. S., \& Pickering, D. J. (2003). Classroom management works. Alexandria, VA: ASCD.

Meador, D. (2014). Classroom management strategies for teachers. Retrieved from www.teachingabout.com/.../

McCreary, R. (2014). Classroom management definition. Retrieved from www.ehow.com/about_5438989...

Monjardin-Esdicul, A. (2009). Classroom and learning management.8th conference of Philippine schools, May 4-6. Retrieved from www.cfo-pso-org.ph/.../fmal_classroom_...

Ovidijus, R. (2013). Strategic management and planning. Retrieved from www.strategicmanagementinsight.com/.../...

Phillips, M. (2004). A place for learning: The physical environment of classrooms. Retrieved from www.edutopia.org/.../the-physical... 
Shakir, M. (2014). Using Henry Faylor's principles for better classroom management. Public Policy and Administration Research, 4(11), 72-77.

Tan, O. S., Parsons, R. D., Hunsons, S. L., \& Sardo-Brown, D. (2003). Educational psychology. A practitioner - research approach. Australia: Thomson.

Udeozor, R. K. (2012). Promoting effective entrepreneurship education through strategic classroom management. Abuja International Journal of Education and Management Sciences (ABIJEMS), 1(2), 296-312.

Unal, Z., \& Unal, A. (2012). The impact of years of teaching experiencie on the classroom management approaches of elementary school teachers. International Journal of Instruction, 5(2), 41-60. Retrieved from www.e-iji.net/dosyalar/iji_2012_2_3.pdf

\section{Copyright Disclaimer}

Copyright reserved by the authors.

This article is an open-access article distributed under the terms and conditions of the CreativeCommons Attribution license (http://creativecommons.org/licenses/by/3.0/). 